\title{
Hole Making of Inconel 718 Aerospace Alloy
}

\author{
Marek Vrabel ${ }^{1, *}$, Martin Eckstein ${ }^{2}$ \\ ${ }^{1^{*}}$ Technical University of Košice, Faculty of Mechanical Engineering, Department of Manufacturing Technology and Materials, Mäsiarska 74, 04001 \\ Košice, Slovak Republic \\ ${ }_{2}^{2}$ MTU AeroEngines Munich, Dachauer Strasse 665, 809905 Munich, Germany
}

\begin{abstract}
Different surface integrity parameters have become one of the major interest within aero engine components production in the aerospace industry. Hole making process of nickel based super alloy Inconel 718 consists of two machining operations, where drilling is applied to remove stock material and is followed by reaming to meet required quality as well as tolerances of the component prescribed by drawing. In the present work, surface roughness parameters Ra and Rz in terms of machined surface integrity were investigated. Their evaluation was performed with respect to number of machined holes and type of employed cutting tool. The results indicate that use of face-cutting finishers produced holes with lower surface roughness when compared to twist drills. Special attention was paid to ensure that the cutting conditions correspond to the industrial practice. Both cutting tools used in experiments were ground from tungsten carbide.
\end{abstract}

Keywords: hole making; aerospace industry; surface roughness; Inconel 718; tungsten carbide.

\section{Introduction}

It has been well-documented the importance of surface integrity upon performance of machined components [1]. The importance of surface integrity upon performance of machined components has been well - documented. Especially, the safety critical (e.g. aerospace) components that work at cyclic high mechanical loads and elevated temperatures are subject of strict surface integrity checks. Of particular interest are $\mathrm{Ti}$ and Ni-based superalloys used for aeroengine components that work in the areas characterised by high level of mechanical and thermal loads [2], see Fig. 1. Nickelbased alloys constitute the widest group of superalloys and are hardly machined. In general, a nickel-based superalloy chemically contain (by volume) 38-76\% nickel (Ni) more than $27 \%$ chromium (Cr) and $20 \%$ cobalt (Co). These materials are used for the higher corrosion strength and high temperature strength applications [3]. Drilling hole operation in aviation industry is being widely used as supplementary of the other production methods. In a typical machining duration, drilling operation is 30\%, turning $20 \%$, milling $16 \%$, threading 15\%, engraving and discharging $6 \%$ and the other operations are $13 \%$. Therefore, drilling operation has a great importance in the industry [4]. Cemented carbides (WC/Co) are widely used in the industry; both uncoated and coated [5]. When the tool is fresh, the surface roughness values are found to be higher than with slightly used tools, and the tool wear close to its half-life resulted in slightly decreased surface roughness values than during its fresher times. This effect can be 
considered as the 'warming up' of the tool material, because when the tool is first used, there can be micron-level sharp edges or peaks at its surface that can be trimmed out to create a smoother, or at least a better fit between contact surface with the workpiece.

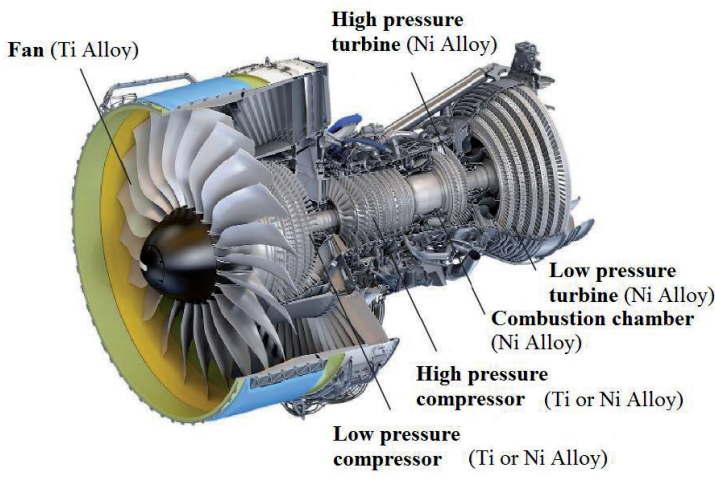

Fig. 1: Cross section of GP7200 turbofan for Airbus A380 [8].

When approaching its half-life, the tool is more fit to the workpiece and the surface roughness values decrease. However, after the half-life, the tool starts wearing even more, and this causes anomalies in the tool-workpiece contact surface, which increases the surface roughness values significantly $[6,7]$.

\section{Experimental procedure}

The cutting experiments were performed on Inconel 718 test pieces, made of a completely heat-treated forging of a genuine turbine disk supplied by MTU-Aero Engines. The diameter of this forging was approx. $680 \mathrm{~mm}$. Subsequently, this forging was turned to a flat disk with a uniform thickness of $22 \mathrm{~mm}$, which afterwards was cut into segments by waterjet-cutting. The hardness of these segments was between 410 and 435 HV30. The experimental drilling tests were performed on a CHIRON FZ15 5-axes milling machine in the machining Laboratory of WZL at the University of Aachen, Germany, see Fig. 2. This machine tool has a maximum spindle power of $24 \mathrm{~kW}$. The test machine was equipped with a SIEMENS Sinumerik 840D controller. Additional data was acquired on production machines on the shop-floor at MTU Aero Engines AG. A very common machine tool, which is applied for the manufacturing of bolt holes in turbine disks at MTU, is a five-axes machining center type MIKRON UCP 1050, equipped with SIEMENS Sinumerik 840D controller. Therefore this machine-type was selected. The design and the technical data of all these production machines at MTU-AE is identical. Both the CHIRON as well as the MIKRON have the capability of applying coolant through an internal coolant supply (in the spindle), through external nozzles, and in both directions simultaneously. Within this paper, study of surface roughness parameters Ra and Rz were evaluated in hole making of Inconel 718 nickel based super alloy.

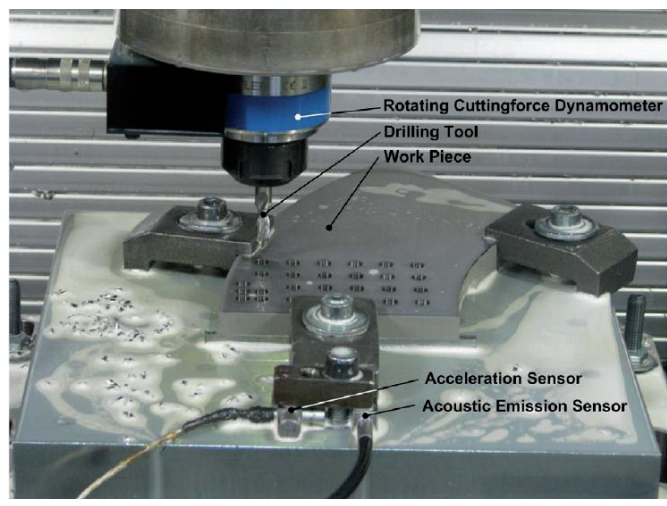

Fig. 2: Experimental set up for drilling test (WZL Aachen) [9].

All cutting tools were made from solid-carbide "EMT210", a fine grain substrate produced by EXTRAMET. The tool diameter of the twist drill was $8.2 \mathrm{~mm}$, the diameter of the face-cutting finisher was defined at $8.5 \mathrm{~mm}$. To clamp the tools, hydraulic expansion chucks HSK63 were applied for all tests. Machining parameters, machining sequence and coolant supply were applied within the range of production parameters of bolt holes in turbine disk manufacturing, see Table 1.

Table 1: Machining parameters employed in hole making process.

\begin{tabular}{|c|c|c|c|}
\hline Machining parameters & Unit & Twist drill & $\begin{array}{l}\text { Face-cutting } \\
\text { finisher }\end{array}$ \\
\hline Radial depth of cut & {$[\mathrm{mm}]$} & 4.1 & 0.15 \\
\hline Cutting speed & {$[\mathrm{m} / \mathrm{min}]$} & 20 & 30 \\
\hline Feed per tooth & {$[\mathrm{mm} / \mathrm{rev}]$} & 0.035 & 0.025 \\
\hline Coolant volume & [l/min] & 12 & 15 \\
\hline
\end{tabular}

In all machining operations coolant was supplied to the cutting zone. During drilling, coolant media was supplied both by high pressure through the 
spindle and by an additional flooding. During finishing, only flooding was performed. The coolant media applied on the machine tool CHIRON FZ $15 S$ was $5 \%$ emulsion (FUCHS Ecocool 2506S). On the production machine MIKRON UCP1050 cutting oil (CASTROL Honilo 971 CF) was applied. On-site surface roughness measurements were performed with a contact stylus surface scanner GARANT Perthometer type "H1". The radius of the scanning diamond was $5 \mu \mathrm{m}$ at a tip opening angle of $90^{\circ}$. This device is capable of recording Ra, Rt and Rmax in accordance with DIN EN ISO 4287. If not outlined separately, the cut-off was adjusted to $4.8 \mathrm{~mm}$. The key aspect of these measurements was to check the surface roughness in machined bolt holes and to compare this data with data taken from bolt holes in engine parts. If not indicated differently, each measurement was performed three times, and the values outlined in figures within this paper represent the arithmetic average of these measurements. In individual cases, the results were verified on a coordinate measurement machine.

\section{Results and Discussion}

The evolution of surface roughness $\mathrm{Ra}$ and $\mathrm{Rz}$, both for drilling and for finishing, is outlined in Fig. 3 and Fig. 4, respectively.

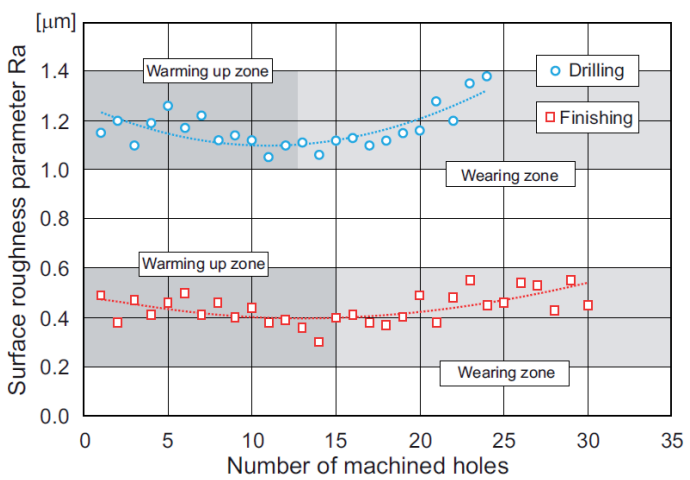

Fig. 3: Evaluation of surface roughness parameter Ra.

Second grade polynomial regression curves illustrate that the overall trend for drilling and finishing is similar. Initially, surface roughness decreases with increasing number of holes representing an increasing cutting length. After approximately 12 drilled holes and approximately 15 finished holes, the surface roughness gets worse again. This characteristic can be explained by two concurrent wear mechanisms that occur simultaneously on the cutting flutes. The initial decrease of surface roughness may be caused by rounded cutting edges and tool corners. They have the potential to improve the kinematic surface roughness of the workpiece although all other parameters of the cutting process itself remain the same. This means that tool wear is not only a uniform removal of tool material from the flank, but predominantly a removal of cutting substrate from exposed areas of the tool.

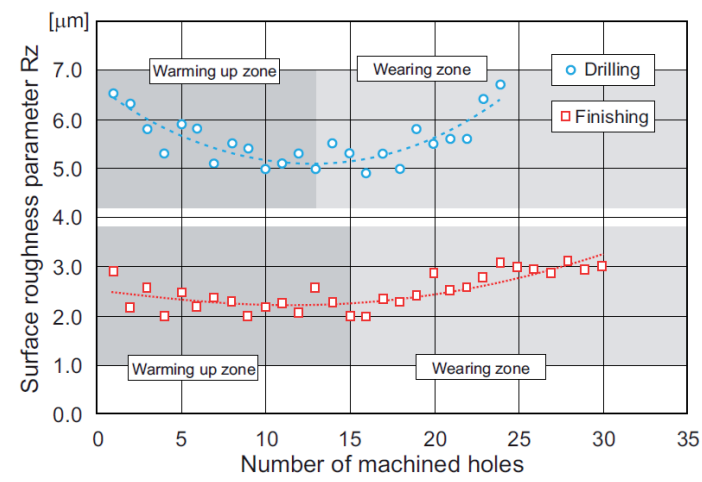

Fig. 4: Evaluation of surface roughness parameter Rz.

Tool wear first leads to a "polishing" and later to a corner rounding of the cutting edge in the transition zone between rake and flank. This corner rounding increases with the cutting length of the tool and may progress to a point, where high cutting forces create extreme pressure in the contact zone between tool and workpiece. Subsequently, the weakest spot of the cutting lip fails. If the tool substrate cannot endure the machining pressure any more, it usually reacts with micro cracks and chip - pings. This creates a new distribution of stress along the active cutting lip. In case, tool wear progresses even beyond, a new local concentration of stress can occur and the cutting lip chips again. With increasing tolerances of the tool geometry and increasing imperfections in structure of the tool material, this process becomes less and less predictable.

\section{Conclusion}

The use of reaming operation with face cutter finisher produced holes with lower surface roughess as expected. The effect of so called "tool material warming up" has been confirmed during drilling and reaming, too. The surface roughness generated on the machined samples fulfils the requirements for bolt holes in aeroengine parts. Future work will 
focus on tool wear evaluation and its influence on formation of different surface integrity variables (surface drag, deformed grains, cracking, debris, feed marks, carbide particles, surface cavities, adhered material particles, surface plucking, slip zones, and redeposited materials). According to Thakur and Ganopadhyay [10], real time process control with advanced sensor-based technologies is an emerging methodology which would enable effective online assessment and control of quality of the components. Looking even further into the future of manufacturing, highly stressed engine components may be processed applying monitoring systems with distributed sensing capabilities. Perhaps this could be combined with a knowledge base on the occurrence of manufacturing anomalies such as white etching layer. There is already a name for this kind of system. It is commonly referred to as a "cyber-physical system".

\section{Acknowledgements}

This work was supported by the Slovak Research and Development Agency under the contract No D07RP-0014-09 and bilateral project APVVSK-SRB-2013-0037 "Implementation of the artificial intelligence into optimization of the selected advanced removal processes" as well as the project VEGA 1/0434/15 "Research on process dependent interface when milling with small diameter of end mill cutters".

\section{References and Notes}

[1] Jawahir, I. S., Brinksmeier, E., M'Saoubi, R., Aspinwall, D. K., Outeiro, J. C., Meyer, D. (2011). Surface Integrity in Material Removal Processes: Recent Advances. Annals of the CIRP, 60, 2, 603-626.

[2] M'Saoubi, R., Axinte, D., Herbert, Ch., Hardy, M., Salmon, P. (2014). Surface integrity of nickel-based alloys subjected to severe plastic deformation by abusive drilling. CIRP Annals - Manufacturing Technology, 63, 61-64.

[3] Ezugwu, E. O., Bonney, J., Yamane, Y. (2003). An overview of the machinability of aero - engine alloys, Journal of Material Processing Technology, 134, 233-235.

[4] Rivero, A., Aramendi, G., Herraz, S., Lopez de Lacalle, L. N. (2006). An experimental investigation of the effect of coatings and cutting parameters on the dry drilling performance of aluminium alloys. Journal of Advanced Manufacturing Technology, 28, 1-11.

[5] Durul, M., Tugrul, O. (2011). Machining induced surface integrity in titanium and nickel alloys: A review. International Journal of Machine Tools \& Manufacture, 51, 250-280.

[6] Che-Haron, A., Jawaid, A. (2005). The effect of machining on surface integrity of titanium. Journal of Material Processing
Technology, 166, 188-192.

[7] Che-Haron, A. (2001). Tool life and surface integrity in turning titanium alloy. Journal of Materials Processing Technology, 118, 231-237.

[8] Engine Alliance, http://www.enginealliance.com/gp7200. html, 12.03.2016.

[9] Arrazola, J. P. (2001). ACCENT Project - Adaptive Control of Manufacturing Processes for a New Generation of Jet Engine Components, Deliverable 3.1 Sensor system definition

[10] Thakur, A., Gangopadhyay, S. (2016). State-of-the-art in surface integrity in machining of nickel-based super alloys. International Journal of Machine Tools \& Manufacture, 100, 25-54.

\section{Biographical notes}

Marek Vrabel,' Ing., Ph.D., born 16th July 1985 in Prešov; graduated from Technical University of Košice, Faculty of Mechanical Engineering in the field of machining technology, in 2009. Position: Research fellow, Department of Manufacturing Technology and Materials; Specialization: Machining operations, Cutting tools, and Process Monitoring. Participated in several projects with national as well as international consortium. Attended several internships and short term visits all over the Europe (Sweden, Germay, Spain, UK a.o). Author and co-author of several publication in scientific databases (Current Contents, Scopus, WOS)

Martin Eckstein, Dipl-Ing., Ph.D., born 20th July 1961 in Coburg, Germany, graduated from the Technical University of Munich in 1986. Current position: Auditor for the production of security of highly stressed turbine components. The audits include the MTU Aero Engines facility in Munich as well as suppliers all over the world (Nord America, Russia or Middle East). Managed several international technology projects for machining, process monitoring as well as coolant application. He has authored several scientific publications, journals, conferences and is an inventor of few patents. 